BMJ Open

Ophthalmology

\title{
Progression to blindness in 20 years among patients with glaucomatous visual field loss in a tertiary hospital in the Philippines
}

\author{
Cathleen Camille Cabrera, Joseph Anthony Tumbocon, John Mark de Leon
}

To cite: Cabrera CC, Tumbocon JA, de Leon JM. Progression to blindness in 20 years among patients with glaucomatous visual field loss in a tertiary hospital in the Philippines. BMJ Open Ophthalmology 2020;5:e000424. doi:10.1136/ bmjophth-2019-000424

Received 3 December 2019 Revised 11 March 2020 Accepted 27 March 2020

\section{Check for updates}

(c) Author(s) (or their employer(s)) 2020. Re-use permitted under CC BY-NC. No commercial re-use. See rights and permissions. Published by BMJ.

Eye Institute, St. Luke's Medical Center, Quezon City, Philippines

Correspondence to Dr John Mark de Leon; jmarkmd1@yahoo.com

\section{ABSTRACT}

Objective To determine visual field (VF) rates of change among patients with glaucomatous VF loss and proportion of those becoming blind based on residual life expectancy and factors associated with fast progression.

Methods and analysis This was a retrospective study of the VFs of patients with glaucomatous VF defects in at least one eye. Baseline and final VFs were reviewed. Rates of VF change (decibels (dB)/year) for each eye, together with the residual life expectancy based on age and sex, were used to predict mean deviation/defect (MD) at the end of expected lifetime. Blindness was defined if computed MD was $22 \mathrm{~dB}$ (Octopus) or $-22 \mathrm{~dB}$ (Humphrey) or worse in the better eye. Factors associated with fast progression ( $>1 \mathrm{~dB} /$ year for 0ctopus or $<-1 \mathrm{~dB} /$ year for Humphrey) and blindness were determined.

Results There were 1016 eyes of 583 patients eligible. There was decline in VF MD/year in 613/1016 (60.3\%), $95 \% \mathrm{Cl}(57.3 \%$ to $63.3 \%)$ of eyes; however, only $98 / 1016$ $(9.7 \%), 95 \% \mathrm{Cl}(7.9 \%$ to $11.5 \%)$ of eyes showed fast progression. Among patients with bilateral VFs, $43 / 433$ $(9.9 \%), 95 \% \mathrm{Cl}(7.1$ to 12.8$)$ of eyes were predicted to progress to blindness. In multivariate analysis, factors associated with fast progression were baseline MD $(p<0.001)$ and male sex $(p=0.041)$. Factors associated with blindness were age $<60$ years $(p=0.003)$, baseline MD ( $p=0.022)$, bilateral glaucomatous VF defects $(p=<0.001)$ and fast progression $(p<0.001)$.

Conclusion Patients reaching blindness in a routine clinical setting was $10 \%$. Because of association of age and baseline MD on blindness, early disease detection is important. VF progression rates and residual life expectancy must be incorporated in glaucoma care.

Glaucoma is a progressive disease that causes optic nerve head and visual field (VF) changes. Intraocular pressure (IOP) is considered the only modifiable risk factor in glaucoma and it is often given a significant role during treatment decisions. ${ }^{1}$ However, because functional vision is a major determinant of quality of life, the rate of VF progression should be included in clinical management. The most common indices (depending on the instrument) to monitor for VF change are the mean defect or deviation (MD) and the loss variance

\section{Key messages}

What is already known about this subject?

A UK study revealed that the developement of blindness using visual fields in a clinic setting is about $5 \%$.

\section{What are the new findings?}

- Our study in the Philippines showed it is $10 \%$.

How might these results change the focus of research or clinical practice?

- The rates of visual field progression and the expected life expectancy are important considerations in glaucoma care.

(LV) or pattern standard deviation (PSD). $\mathrm{MD}$ represents the difference in the overall sensitivity of the VF compared with the agematched normal sensitivity values. ${ }^{2} \mathrm{LV}$ or PSD, which is more specific for localised VF loss, has been shown to underestimate true change as some diffuse loss also occurs in glaucoma. In the Early Management Glaucoma Trial and Collaborative Normal Tension Glaucoma Study, the mean rate of progression was -1.08 decibels $(\mathrm{dB}) /$ year and -0.2 to $-2 \mathrm{~dB} /$ year, respectively. ${ }^{45}$ In a study by Heijl $e$ e al, among patients with glaucoma under clinical care, the mean rate of progression was $-0.80 \mathrm{~dB} /$ year. However, fast progressors were also common. ${ }^{6}$ Determining rate of change would entail frequent VF testing to establish a trend. Once detected, the individual's residual life expectancy or life expectancy adjusted for age must be taken into consideration. ${ }^{7}$ Using these data, individualised care and avoidance of excess treatment and monitoring can be attained.

VF rates of change and the risk factors for progression among patients with glaucoma have been investigated in numerous studies. ${ }^{8}$ However, most of these studies are limited to the VF result only and did not consider estimates of blindness based on a 
patient's residual life expectancy. Furthermore, these types of studies are currently lacking in the Philippines. The significance of providing local data on the status of glaucomatous VF loss and the number of patients at risk of becoming blind within their lifetime will help determine whether efforts in the management of those with glaucomatous VF damage are adequate and properly administered. This study aims to help direct future efforts and resources in the care of patients with glaucoma.

The goal of this study is to provide information on the current trend of field progression among patients with glaucomatous field loss using data collected from a Philippine tertiary hospital. Specifically, this study aims to determine the rates of field change based on MD, the proportion of patients that will become blind during their lifetime and the factors associated with a fast rate of field loss and progression to blindness at death.

\section{METHODS}

This was a retrospective cohort study using VF test data done at St. Luke's Medical Center, Quezon City, Metro Manila, Philippines of patients with glaucomatous VF defects.There was no direct patient and public involvement in this study as the anonymised VF data were collected and analysed without compromising data privacy of the subjects.

Patients with glaucomatous VF defects with at least five reliable VF tests using the same test programme for at least 3 years from July 1998 to April 2018 were included in the study. For the Octopus VF, a glaucomatous VF defect was defined as (1) $\mathrm{MD}>2 \mathrm{~dB}$ and/or $\mathrm{LV}>6 \mathrm{~dB}$; and (2) presence of at least three contiguous abnormal points with $\mathrm{p}$ values less than $5 \%$ in the arcuate area in the pattern deviation plot on two consecutive examinations. ${ }^{9}$ For the Humphrey VF, a glaucomatous VF defect was defined as (1) a glaucoma hemifield test outside normal limits on at least two fields; (2) a cluster of three or more non-edge points, two of which are depressed on the pattern deviation plot at a $p$ value of less than $5 \%$ and one of which is depressed at a $p$ value of less than $1 \%$ on two consecutive fields; or (3) a pattern standard deviation (PSD) that occurs in less than 5\% of normal fields on two consecutive fields. ${ }^{10}$ Unreliable VFs, defined to have a false-positive score of $20 \%$ or more, false-negative score of $33 \%$ or more, or fixation loss score of $20 \%$ or more, and a reliability factor of $>15 \%$ (Octopus) were excluded. Patients 18 years old and below, as well as those who are blind at the start of the study (an MD of $\geq 22 \mathrm{~dB}$ for the Octopus or $\leq-22 \mathrm{~dB}$ for the Humphrey in the better eye) ${ }^{11}$ based on the baseline MD, were not included in the study.

VF test results of patients with glaucomatous VF defects were reviewed. Only VFs recorded on the Octopus VF (Haag-Streit, Koeniz, Switzerland) using the tG2 programme (central 30 degrees, size III white stimulus and TOP strategy) or the dG2 programme (central 30 degrees, size III white stimulus and Dynamic strategy) or on the Humphrey VF (Carl Zeiss Meditec, USA) using the
Table 1 Age-adjusted life expectancy based on the WHO Global Health Observatory data repository on the Philippines for the year $2015^{12}$

\begin{tabular}{llll}
\hline & & Male & Female \\
\hline Expectation of life & <1 year & 65.3 & 72 \\
& 1-4 years & 66 & 72.4 \\
& 5-9 years & 62.4 & 68.8 \\
& 10-14 years & 57.5 & 63.9 \\
& 15-19 years & 52.7 & 59.1 \\
20-24 years & 48 & 54.3 \\
25-29 years & 43.5 & 49.5 \\
30-34 years & 39.1 & 44.8 \\
35-39 years & 34.7 & 40.1 \\
40-44 years & 30.4 & 35.5 \\
45-49 years & 26.2 & 31 \\
50-54 years & 22.3 & 26.7 \\
55-59 years & 18.7 & 22.5 \\
60-64 years & 15.5 & 18.6 \\
65-69 years & 12.7 & 14.9 \\
70-74 years & 10 & 11.5 \\
75-79 years & 7.5 & 8.5 \\
80-84 years & 5.5 & 5.9 \\
85+ years & 4 & 4 \\
\hline
\end{tabular}

WHO, World Health Organization.

30-2 programme (central 30 degrees, size III white stimulus and SITA-Fast or Standard strategy) were included in the study. The presence of a glaucomatous pattern of VF defects was determined based on the criteria stated previously. To eliminate learning effects, the first VF examination was disregarded.

The following data from the VF printout were obtained, tabulated and organised using Microsoft Excel 2011: birthdate, ages on the first and last VF test, sex, type of VF programme used, duration of follow-up, number of $\mathrm{VF}$ tests performed, baseline and final MD. The first and last recorded MD were referred to as the baseline and final $\mathrm{MD}$, respectively. Rates of MD change were calculated in $\mathrm{dB} /$ year using ordinary least squares regression. $\mathrm{MD}$ at the expected death was determined by multiplying the rate of change and the patient's residual life expectancy. Residual life expectancies, based on age and sex, were collected from the World Health Organization Global Health Observatory data repository on the Philippines for the year 2015 (table 1). ${ }^{12}$

An MD of $22 \mathrm{~dB}$ (Octopus) or $-22 \mathrm{~dB}$ (Humphrey) in the better eye is the value that corresponds to the US Social Security Act definition of 'statutory blindness'. ${ }^{11}$ When determining blindness, both eyes had reached the necessary level of VF loss. If patients had fewer than five VFs performed in one of their eyes, then their baseline MDs were recorded and the eyes were either deemed to be stable $(0 \mathrm{~dB} /$ year $)$ or progressing $(1.0 \mathrm{~dB} /$ year for 


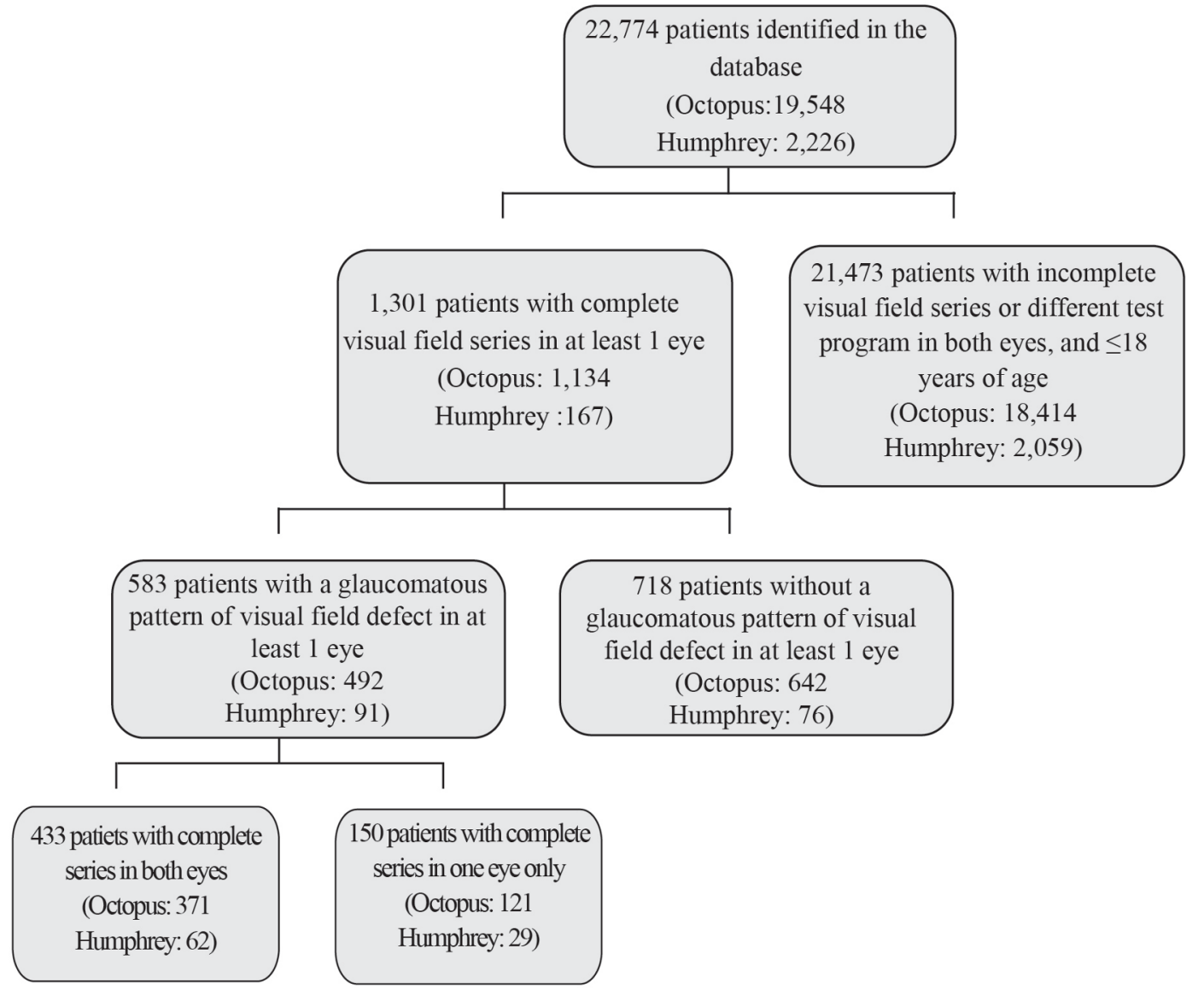

Figure 1 Flow chart of patient selection process.

Octopus or $-1.0 \mathrm{~dB} /$ year for Humphrey) representing a 'best'-case and 'worst'-case scenario, respectively. If there was no recorded VF for the other eye, the eye was recorded as either healthy or blind representing a 'best'case and 'worst'-case scenario, respectively. Fast rate of progression was defined as VF worsening of $>1 \mathrm{~dB} /$ year (Octopus) or $<-1 \mathrm{~dB} /$ year (Humphrey). ${ }^{6}$

\section{RESULTS}

Out of the 22,774 patients identified in the Octopus $(19,548)$ and Humphrey $(2,226)$ VF databases, only 583 patients met the inclusion criteria (figure 1). Four hundred thirty-three patients had VF series in both eyes, while 150 patients had series in only one eye. The characteristics of the patients in the study are given in table 2. Overall, majority of patients were female $(62.4 \%)$ with a mean baseline age of $61.1 \pm 12.6$ years and a mean final age of $66.2 \pm 12.5$. The mean residual life expectancy based on the final age was $18.8 \pm 9.6$ years. The most common VF programme used was the Octopus tG2 (50.9\%) with a mean follow-up period of $5.1 \pm 2.3$ years and $6.6 \pm 2.0$ examinations.

Compared with the mean baseline MD, a significant $(\mathrm{p}<0.001)$ decline in the mean final MD was only observed for the better eye using the Octopus VF. The other MD changes were non-significant (table 2, figure 2A,B).
Figure 3 demonstrates the distribution of MD rates of change in all eyes. It is evident that majority of eyes worsened at a rate between 0 and $0.5 \mathrm{~dB} /$ year for the Octopus $(35.7 \%, 95 \%$ CI $32.5 \%$ to $38.7 \%)$ and improved at the same rate for the Humphrey VF $(32.7 \%$, CI $25.3 \%$ to $40.1 \%$ ). Overall, $60.3 \%$ (CI $57.3 \%$ to $63.3 \%$ ) showed a decline in MD per year; however, only $9.7 \%$ (CI $7.9 \%$ to $11.5 \%$ ) showed fast progression. Noticeably, 39.3\% (CI $36.3 \%$ to $42.3 \%$ ) showed improvement.

Table 3 shows the univariate analysis of the factors associated with a fast rate of progression. Majority of the fast progressors were male, 60 years old and above, and had a glaucomatous pattern of VF defect on both eyes. Their mean baseline MD was 7.7 \pm 3.9 for the Octopus and $-9.5 \pm 4.8$ for the Humphrey.

Baseline MD was shown to be the only statistically significant the factor associated with a fast rate of progression but after controlling for the baseline MD in the multivariate analysis (table 4), sex became statistically significant as well. Males have 1.56 times the odds of fast progression, holding the baseline MD constant while the odds of fast progression decreases by $6 \%$ for every $1 \mathrm{~dB}$ worsening in baseline $\mathrm{MD}$, holding sex constant.

Only $9.9 \%$ (95\% CI 7.11 to 12.75 ) of patients with $\mathrm{VF}$ series in both eyes progressed to blindness in their expected lifetime (table 5). The 'best-case scenario' 
Table 2 Patient demographics

\begin{tabular}{|c|c|c|c|c|}
\hline Measure & All patients, $n=583$ & \multicolumn{2}{|c|}{ Patients with series in both eyes, $n=433$} & $\begin{array}{l}\text { Patients with series in one eye } \\
\text { only, } n=150\end{array}$ \\
\hline Male & $219(37.6)$ & \multicolumn{2}{|l|}{$137(31.6)$} & $82(54.7)$ \\
\hline Female & $364(62.4)$ & \multicolumn{2}{|l|}{$296(68.4)$} & $68(45.3)$ \\
\hline Range & 20 to 90 & \multicolumn{2}{|l|}{24 to 86} & 20 to 90 \\
\hline \multicolumn{5}{|l|}{ Final age } \\
\hline Mean \pm SD & $66.2 \pm 12.5$ & \multicolumn{2}{|l|}{$66.8 \pm 11.5$} & $64.5 \pm 15.0$ \\
\hline Range & 25 to 93 & \multicolumn{2}{|l|}{31 to 91} & 25 to 93 \\
\hline \multicolumn{5}{|l|}{ VF programme, n (\%) } \\
\hline Octopus dG2 & $195(33.4)$ & \multicolumn{2}{|l|}{$143(33.2)$} & $52(34.7)$ \\
\hline Octopus tG2 & $297(50.9)$ & \multicolumn{2}{|l|}{$228(52.4)$} & $69(46.0)$ \\
\hline Humphrey $30-2$ & $91(15.6)$ & \multicolumn{2}{|l|}{$62(14.4)$} & $29(19.3)$ \\
\hline \multicolumn{5}{|l|}{ Follow-up period (years) } \\
\hline Mean \pm SD & $5.1 \pm 2.3$ & \multicolumn{2}{|l|}{$5.2 \pm 2.3$} & $4.6 \pm 2.1$ \\
\hline Range & 2 to 15 & \multicolumn{2}{|l|}{2 to 15} & 2 to 14 \\
\hline \multicolumn{5}{|l|}{ Number of VF tests } \\
\hline Mean \pm SD & $6.6 \pm 2.0$ & \multicolumn{2}{|l|}{$6.7 \pm 2.0$} & $6.4 \pm 1.9$ \\
\hline Mean \pm SD & & $-5.2 \pm 6.7$ & $-12.6 \pm 7.1$ & $-14.1 \pm 7.8$ \\
\hline Range & & -21.8 to 0.9 & -22.4 to -2.1 & -21.8 to -2.4 \\
\hline Final MD & & & & \\
\hline Octopus & & & & \\
\hline Mean \pm SD & & $6.3 \pm 5.2$ & $11 \pm 5.8$ & $13.2 \pm 5.8$ \\
\hline Range & & -2 to 21.3 & 1.9 to 22.9 & 2.7 to 22.5 \\
\hline Humphrey & & & & \\
\hline Mean \pm SD & & $-4.8 \pm 5.8$ & $-13.3 \pm 7.0$ & $-14.9 \pm 7.5$ \\
\hline Range & & -20.9 to 0.7 & -23.1 to -2.6 & -20.0 to -3.7 \\
\hline Rate of VF field loss (dB/year) & & & & \\
\hline Octopus & & & & \\
\hline Mean \pm SD & & $0.17 \pm 0.69$ & $0.16 \pm 0.87$ & $0.30 \pm 0.79$ \\
\hline Range & & -3.40 to 4.10 & -2.90 to 3.53 & -2.00 to 3.37 \\
\hline Humphrey & & & & \\
\hline Mean \pm SD & & $0.08 \pm 0.40$ & $-0.15 \pm 0.68$ & $-0.20 \pm 0.80$ \\
\hline Range & & -0.75 to 1.56 & -1.97 to 1.68 & -1.90 to 1.50 \\
\hline
\end{tabular}

MD, mean deviation ; SD, standard deviation ; VF, visual field. 


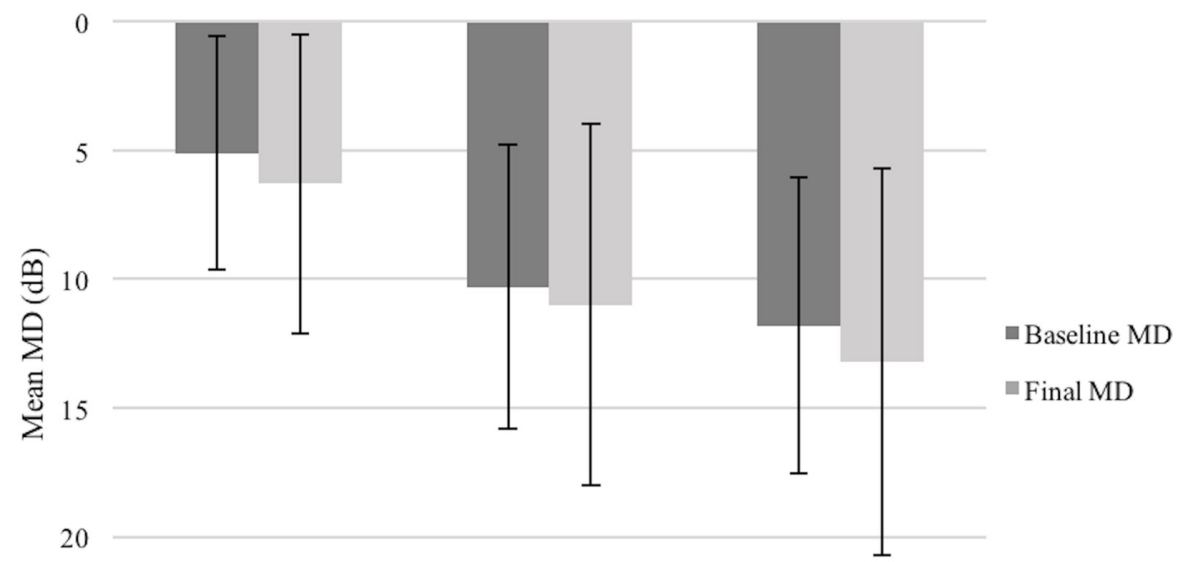

$A^{25} \quad$ Better Eye $\quad$ Worse Eye $\quad$ One Eye

5

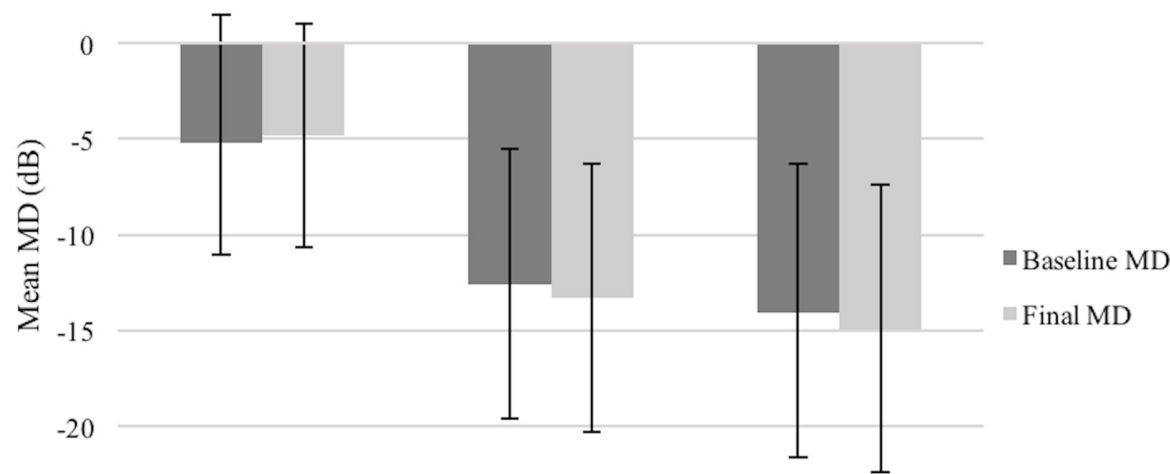

B $-25$ Better Eye

Worse Eye One Eye

Figure 2 Mean baseline and final MD of eyes included in the study for the Octopus VF (A) and Humphrey VF (B).

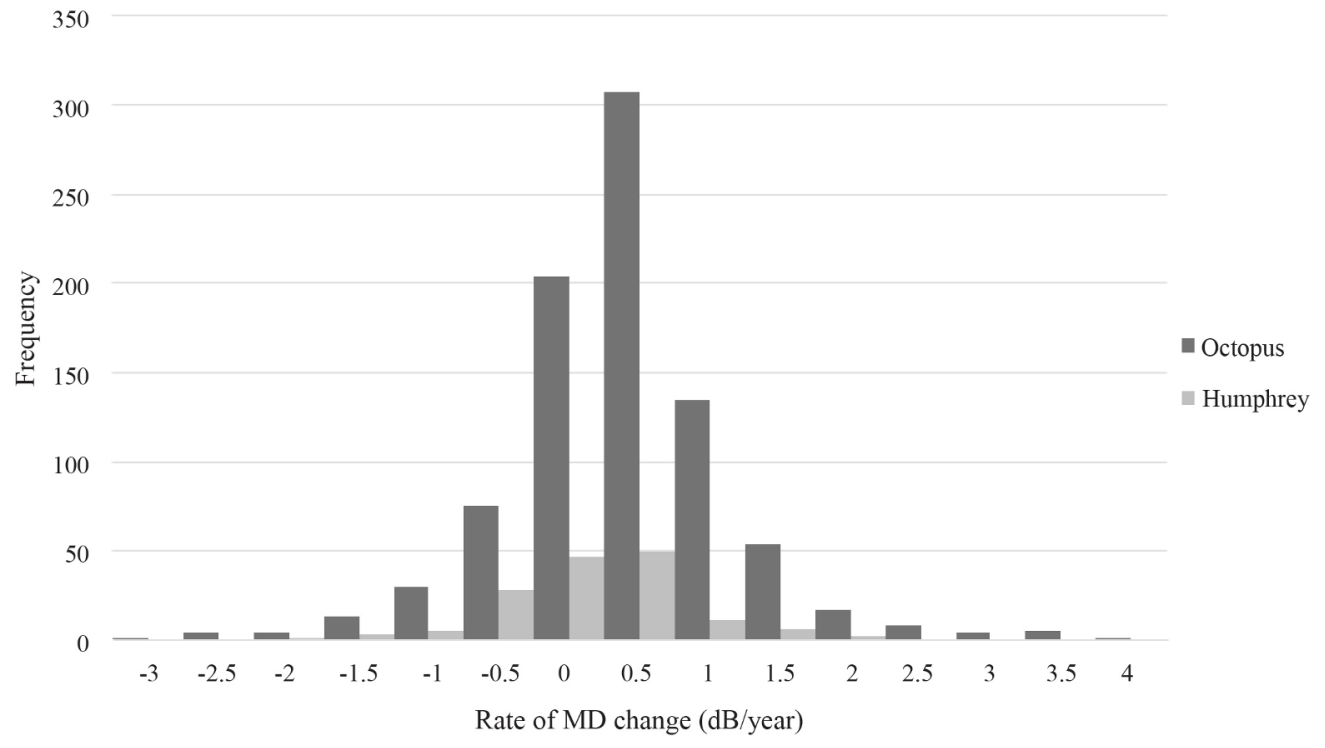

Figure 3 Distribution of the rates of progression of all eyes expressed in $\mathrm{dB} /$ year. 


\begin{tabular}{|c|c|c|c|}
\hline Factor & Fast rate of progression $\mathrm{MD}, \mathrm{n}(\%)$ & $P$ value & ORs $(95 \% \mathrm{Cl})$ \\
\hline \multicolumn{4}{|l|}{ Sex } \\
\hline Male & $43(13.7)$ & 0.135 & 1.37 (0.91 to 2.08$)$ \\
\hline Female & $60(9.1)$ & & \\
\hline \multicolumn{4}{|l|}{ Age group } \\
\hline Less than 60 years old & $38(9.3)$ & 0.455 & 0.85 (0.56 to 1.30$)$ \\
\hline 60 years old and above & $65(10.8)$ & & \\
\hline Baseline MD & & 0.001 & 0.91 (0.86 to 0.94$)$ \\
\hline \multicolumn{4}{|c|}{ Presence of glaucomatous visual field defect } \\
\hline Bilateral & $55(11.4)$ & 0.232 & $1.28(0.85$ to 1.93$)$ \\
\hline Unilateral & $48(9.1)$ & & \\
\hline
\end{tabular}

MD, mean defect or deviation.

revealed a slight increase to $12.4 \%$ (95\% CI 9.68 to 15.02$)$ and a further increase to $15.8 \%$ (95\% CI 12.82 to 18.74 ) for the 'worst-case scenario'.

The factors associated with blindness at expected death using univariate and multivariate analysis are displayed in tables 6 and 7, respectively.

Majority of patients who were predicted to reach blindness were male, less than 60 years of age, had a glaucomatous pattern of VF defect on both eyes, and had a progression rate of $>1 \mathrm{~dB}$ /year for the Octopus and $<-1 \mathrm{~dB} /$ year for the Humphrey VF. The mean initial MD among these patients was $8.2 \pm 4.2$ (Octopus). Less than 60 years of age, baseline MD, presence glaucomatous VF defect pattern on both eyes and a fast rate of progression were all statistically significant factors associated with blindness at death. For every $1 \mathrm{~dB}$ worsening in baseline $\mathrm{MD}$, the odds of becoming blind at death increased by about $10 \%$ holding age, presence glaucomatous $\mathrm{VF}$ defect pattern on both eyes and the MD rate of progression constant.

\section{DISCUSSION}

This study revealed an overall worsening of the MD in the final VF examination (except for the better eyes tested using the Humphrey VF). The difference in the mean final MD from the initial mean baseline MD, however, was not significant (except for the better eyes tested in the Octopus VF) and was not high (up to less than $1.5 \mathrm{~dB}$ ). Given the mean follow-up period of around 5 years, this would indicate a progression rate of only about $0.3 \mathrm{~dB} /$ year (Octopus) or $-0.3 \mathrm{~dB} /$ year (Humphrey). Using the individual progression rates and residual life

\begin{tabular}{|c|c|c|c|}
\hline & ORs & $95 \% \mathrm{Cl}$ & $P$ value \\
\hline Sex (M:F) & 1.56 & 1.1 to 2.41 & 0.041 \\
\hline Baseline MD & 0.94 & 0.83 to 0.91 & $<0.001$ \\
\hline
\end{tabular}

F, female; M, male; MD, mean defect or deviation. expectancy, almost $10 \%$ were predicted to become blind in their expected lifetime. Depending on the reasons for testing only one eye, this number can reach up to $15.8 \%$ ('worst-case scenario'). Although these results appear optimistic, they are less positive compared with the study of Saunders $e t$ al where in cohorts in UK clinics only $5.2 \%$ were shown to progress to blindness. ${ }^{13}$ Also, considering that the progression rate used in their study was $-1.5 \mathrm{~dB}$ / year compared with $-1.0 \mathrm{~dB} /$ year in our study for worstcase scenario, our results still showed a higher number of patients who will go blind. For better comparison, we patterned the criteria for blindness in our study with their study (MD worse than or equal to $22 \mathrm{~dB}$ ). Patients included in their study, however, were being monitored at specialist glaucoma clinics, whereas the patients in our study were not treated exclusively by glaucoma specialists. Furthermore, blindness in our study could have been underestimated since the basis of the diagnosis of glaucoma was simply based on VF and several subjects may have not had glaucoma in the first place since structural correlation is also very important in making the diagnosis of glaucoma. This study was only based on VF follow-ups with no data on other clinical aspects limiting the veracity of the true clinical diagnosis of glaucoma. In addition, other factors (IOP control, type of glaucoma, compliance to medications) which were not included in the study may also have contributed to this difference. Our institute is a tertiary hospital with an eye institute comprising general ophthalmologists and ophthalmology subspecialists. It

Table 5 Proportion of patients likely to become blind in the course of their lifetime

\begin{tabular}{lc}
\hline Blindness at death & \% Blind $(95 \%$ Cl) \\
\hline $\begin{array}{l}\text { Patients with series in both eyes, } \\
n=433\end{array}$ & $9.9(7.11$ to 12.75$)$ \\
$\begin{array}{l}\text { All patients best-case scenario, } \\
n=583\end{array}$ & $12.4(9.68$ to 15.02$)$ \\
$\begin{array}{l}\text { All patients worst-case scenario, } \\
n=583\end{array}$ & $15.8(12.82$ to 18.74$)$ \\
\hline
\end{tabular}




\begin{tabular}{|c|c|c|c|}
\hline Factor & Expected blind at death MD, $\mathrm{n}(\%)$ & $P$ value & ORs $(95 \% \mathrm{Cl})$ \\
\hline \multicolumn{4}{|l|}{ Sex } \\
\hline Male & $17(12.4)$ & 0.25 & $1.46(0.76$ to 2.79$)$ \\
\hline Female & $26(8.8)$ & & \\
\hline \multicolumn{4}{|l|}{ Age group } \\
\hline Less than 60 years old & $24(13.8)$ & 0.030 & 2.00 (1.06 to 3.78$)$ \\
\hline 60 years old and above & $19(7.4)$ & & \\
\hline Baseline MD & & $<0.001$ & 1.14 (1.19 to 1.31$)$ \\
\hline \multicolumn{4}{|c|}{ Presence of glaucomatous visual field defect } \\
\hline Bilateral & $38(16.5)$ & $<0.001$ & 7.76 (2.99 to 20.13$)$ \\
\hline Unilateral & $5(2.5)$ & & \\
\hline \multicolumn{4}{|l|}{ MD rate of progression } \\
\hline Fast & $21(65.6)$ & $<0.001$ & $32.72(14.03$ to 76.29$)$ \\
\hline $\begin{array}{l}\leq 1 \mathrm{~dB} / \text { year (Octopus), } \geq-1 \mathrm{~dB} / \text { year } \\
\text { (Humphrey) }\end{array}$ & $22(5.5)$ & & \\
\hline
\end{tabular}

$\mathrm{MD}$, mean defect or deviation.

also has a laser and diagnostic centre where different procedures are done and where ophthalmologists or glaucoma specialists from different hospitals can refer their private patients to. The source of our data was from the eye diagnostic centre where we did not have access to the clinical records of the patients who underwent the $\mathrm{VF}$ tests.

The rate of progression of the worse eye in this study with an average follow-up of 5 years using the Humphrey $\mathrm{VF}$ was $-0.3 \mathrm{~dB} /$ year, slightly worse than the 5 -year study of Verma et al, which was $-0.12 \pm-0.51 \mathrm{~dB} /$ year also using the Humphrey; however, they used a software (Progressor) converting Humphrey sensitivities to pointwise trend analysis. ${ }^{14}$ We used a global index specifically MD trend analysis. Also, their patients included only patients with primary angle closure glaucoma, while this study's patients had no specific glaucoma diagnosis and may not even have had any glaucoma at all so direct comparisons on rates of progression may not be possible.

Baseline MD was found to be positively associated with blindness at death. The mean baseline MD among patients who were predicted to reach blindness in this study was $8.2 \pm 4.2$ (Octopus). This is consistent with the study of Saunders et al which demonstrated that most patients at risk of blindness had greater VF defect (MD

\begin{tabular}{|c|c|c|c|}
\hline & ORs & $95 \% \mathrm{Cl}$ & $P$ value \\
\hline Age group & 3.72 & 1.58 to 8.77 & 0.003 \\
\hline Bilaterality & 9.83 & 2.77 to 34.82 & $<0.001$ \\
\hline Baseline MD & 1.10 & 1.14 to 1.34 & 0.022 \\
\hline Rate of progression & 59.72 & 19.29 to 184.86 & $<0.001$ \\
\hline
\end{tabular}

MD, mean defect or deviation. worse than $-6 \mathrm{~dB}$ in Humphrey) at baseline. ${ }^{13}$ A person with a worse $\mathrm{MD}$ will be at a higher risk for blindness since he or she will be much closer to the 'blindness threshold' compared with a person with a better MD provided that all other influencing factors are equal. This supports the importance of early disease detection.

Several treatment trials have demonstrated the relationship between initial MD and progression rates. In the Ocular Hypertension Treatment Study and Early Management Glaucoma Trial, a worse baseline VF MD led to increased progression rates compared with those with a better MD. ${ }^{45}$ In contrast, a study by Forchheimer et al found out that baseline VF MD had no effect on the rate of VF change. ${ }^{16}$ This study, on the other hand, indicated a negative association between baseline $\mathrm{MD}$ and fast rate of progression. A similar outcome was also shown in a study by Heijl et al which revealed that worse baseline VF status was associated with a slower rate of progression. ${ }^{6}$ One reason may be the 'floor' effect experienced by severely damaged eyes. That is, a VF with a severe defect cannot progress as much as a field with less damage. ${ }^{6}{ }^{6}$

Fast rate of progression ( $>1 \mathrm{~dB} /$ year for the Octopus and $<-1 \mathrm{~dB} /$ year for the Humphrey VF), another significant factor for blindness, was seen in more than $60 \%$ of patients that were predicted to become blind at death. A similar rate of VF loss was observed in the study by Rossetti $e t a l$, where all eyes that developed blindness worsened at a rate of $-1.1 \mathrm{~dB} /$ year (Humphrey). ${ }^{17}$ Thus, progression rates should be incorporated in glaucoma care to determine whether treatment should be adjusted in order to prevent blindness without overlooking the possibility of 'floor effect' among severely damaged eyes.

Less than 60 years of age was shown to be a significant factor for blindness at death. Patients in this age group have greater residual life expectancy, therefore, are likely to become blind assuming that no treatment changes are 
made. This finding is in contrast to the study of Rossetti et al which revealed that older age was a risk factor for blindness. ${ }^{17}$ A possible explanation for this difference is the fact that blindness was only a predicted outcome in our study and it is presumed that no escalation of treatment is made so that progression is allowed to continue at the same rate until the patient's residual life expectancy. Thus, assuming all other factors are held constant, the total amount of VF decay over a younger patient's lifetime will be greater than that of an older person.

Male sex was found to be a significant factor for a fast rate of progression after controlling for the baseline MD. Although studies on animal models have found evidence on the neuroprotective effects of female sex hormones, human studies have revealed inconsistent results. ${ }^{18}$ Other possible explanations could be a poorer IOP control and compliance, a more aggressive type of glaucoma or the presence of another ocular disease in men.

This study displayed visual loss per year, on average. However, the distribution of the rate of change varied and showed that most eyes only progressed at a rate of 0 to $0.5 \mathrm{~dB}$ /year. Interestingly, approximately $39.3 \%$ of eyes showed improvement in the VF. Saunders et al reported positive MD rates in $33 \%$ of eyes in their study; however, this could be attributed to VF measurement variability. ${ }^{13} \mathrm{~A}$ study by Russell $e t$ al showed that measurement variability increases as the sensitivity decreases to a level of $-10 \mathrm{~dB}$ and peaks at around $-20 \mathrm{~dB} .{ }^{19}$ Improvement could also be due to learning effects. Our study tried to minimise learning effects by eliminating the first VF examination but the Collaborative Initial Glaucoma Treatment Study showed that improvement in the VF was still possible after the succeeding tests. ${ }^{20}$ The effect or treatment of a concomitant ocular disease could also be another reason for improvement on the VF. This, however, was not determined in this study but may be helpful in future studies.

This study had certain limitations. Because of its retrospective design, some data were not available or reviewed. Some eyes with glaucomatous VF damage may not actually have had glaucoma, however, the glaucomatous VF criteria used in this study as well as regular VF monitoring for 3 years makes this unlikely. Procedures done within the study period may have influenced the VF, such as sensitivity improvement with cataract extraction. Other ocular disease/procedures which may have contributed to worsening of the VF were not taken into consideration. However, compared with prospective studies which may have an influence on a patient's adherence to follow-up and treatment, ours represents routine clinical setting which will be of more help to determine whether current efforts to slow down progression are adequate. Furthermore, while other studies have determined blindness based on the final MD, this study predicted blindness based on an individual's residual life expectancy instead. This provides a reflection of how a person's VF will progress if no change in treatment takes place and it underscores the importance on individualised treatment. Another recommendation would perhaps also include visual impairment as an endpoint ( $-14 \mathrm{~dB}$ cut-off) for better comparison with other studies.

In conclusion, this study revealed an overall worsening of the VF MD in the majority of eyes at $0-0.5 \mathrm{~dB}$ / year. This study also showed that most patients under a routine clinical setting will not reach blindness in their lifetime. Baseline MD, less than 60 years of age, presence of glaucomatous VF defect on both eyes and a fast rate of progression $(>1 \mathrm{~dB} /$ year for Octopus and $<-1 \mathrm{~dB} /$ year for Humphrey) were shown to be significant factors for blindness. This study also demonstrated that the rates of progression of eyes had considerable variability, and while the male sex was a significant factor for fast progression, the initial MD exhibited an inverse relationship. Because of the association of age and baseline MD on blindness, the role of early diagnosis is critical in blindness prevention. Rate of progression should also be determined especially among those with less severe VF damage.

Contributors JAJT: responsible for overall content, concept, polishing. CCNC: conduct of the study, manuscript writing, statistics, polishing. JMdL: submission, polishing.

Funding The authors have not declared a specific grant for this research from any funding agency in the public, commercial or not-for-profit sectors.

Competing interests None declared.

Patient and public involvement Patients and/or the public were not involved in the design, or conduct, or reporting, or dissemination plans of this research.

Patient consent for publication Not required.

Ethics approval This research followed the tenets of the Declaration of Helsinki and was approved by the Institutional Review Board of St. Luke's Medical Center.

Provenance and peer review Not commissioned; externally peer reviewed.

Data availability statement All data relevant to the study are included in the article.

Open access This is an open access article distributed in accordance with the Creative Commons Attribution Non Commercial (CC BY-NC 4.0) license, which permits others to distribute, remix, adapt, build upon this work non-commercially, and license their derivative works on different terms, provided the original work is properly cited, appropriate credit is given, any changes made indicated, and the use is non-commercial. See: http://creativecommons.org/licenses/by-nc/4.0/.

ORCID iD

John Mark de Leon http://orcid.org/0000-0003-4101-4794

\section{REFERENCES}

1 Quigley HA, Broman AT. The number of people with glaucoma worldwide in 2010 and 2020. Br J Ophthalmol 2006;90:262-7.

2 Heijl A, Patella V, Bengtsson B. The field analyzer primer: effective perimetry. 4th edn. Dublin, CA: Carl Zeiss Meditec, Inc, 2012.

3 Artes PH, Nicolela MT, LeBlanc RP, et al. Visual field progression in glaucoma: total versus pattern deviation analyses. Invest Ophthalmol Vis Sci 2005;46:4600-6.

4 Leske MC, Heijl A, Hyman L, et al. Predictors of long-term progression in the early manifest glaucoma trial. Ophthalmology 2007;114:1965-72.

5 Anderson DR, Drance SM, Schulzer M, et al. Natural history of normal-tension glaucoma. Ophthalmology 2001;108:247-53.

6 Heijl A, Buchholz P, Norrgren G, et al. Rates of visual field progression in clinical glaucoma care. Acta Ophthalmol 2013;91:406-12.

7 Wesselink C, Stoutenbeek R, Jansonius NM. Incorporating life expectancy in glaucoma care. Eye 2011;25:1575-80.

8 Leske MC, Heijl A, Hussein M, et al. Factors for glaucoma progression and the effect of treatment: the early manifest glaucoma trial. Arch Ophthalmol 2003;121:48-56. 
9 Gonzalez de la Rosa M, Gonzalez-Hernandez M, Garcia Feijoo J, et al. Diagnostic accuracy and reproducibility of tendency oriented perimetry in glaucoma. Eur J Ophthalmol 2006:16:259-67.

10 Nayak B, Dharwadkar S. Interpretation of autoperimetry. J Clin Ophthalmol Res 2014;2:31-59.

11 Lennie P, Van Hemel SB, National Research Council. Visual impairments: determining eligibility for social security benefits. Committee on disability determination for individuals with visual impairments. Division of behavioral and social sciences and education. Washington, DC: National Academy Press, 2002.

12 World Health Organization. Global health observatory data repository. [Data file], 2017. Available: http://apps.who.int/gho/data/ view.main.LT62150?lang=en

13 Saunders LJ, Russell RA, Kirwan JF, et al. Examining visual field loss in patients in glaucoma clinics during their predicted remaining lifetime. Invest Ophthalmol Vis Sci 2014;55:102-9.

14 Verma S, Nongpiur ME, Atalay E, et al. Visual field progression in patients with primary angle-closure glaucoma using pointwise linear regression analysis. Ophthalmology 2017;124:1065-71.
15 Kass MA, Heuer DK, Higginbotham EJ, et al. The ocular hypertension treatment study: a randomized trial determines that topical ocular hypotensive medication delays or prevents the onset of primary open-angle glaucoma. Arch Ophthalmol 2002;120:701-13.

16 Forchheimer I, de Moraes CG, Teng CC, et al. Baseline mean deviation and rates of visual field change in treated glaucoma patients. Eye 2011;25:626-32.

17 Rossetti L, Digiuni M, Montesano G, et al. Blindness and glaucoma: a multicenter data review from 7 academic eye clinics. PLoS One 2015;10:e0136632.

18 Vajaranant TS, Nayak S, Wilensky JT, et al. Gender and glaucoma: what we know and what we need to know. Curr Opin Ophthalmol 2010;21:91-9.

19 Russell RA, Garway-Heath DF, Crabb DP. New insights into measurement variability in glaucomatous visual fields from computer modelling. PLoS One 2013;8:e83595.

20 Gillespie BW, Musch DC, Guire KE, et al. The collaborative initial glaucoma treatment study: baseline visual field and test-retest variability. Invest Ophthalmol Vis Sci 2003;44:2613-20. 